\title{
Digitalization of Market of Compulsory Third Party Car Insurance as a Factor in Overcoming the Crisis in Third Party Only Insurance and Ensuring Economic Security
}

\author{
Verzilin V.A.* \\ The Russian Presidential Academy of National Economy \\ and Public Administration \\ Voronezh, Russian \\ E-mail:kafec@bk.ru
}

\begin{abstract}
Significant moral and material damage to road users and the transportation process resulting from road accidents objectively implies the need for insurance protection of both individuals and legal entities that are direct participants in the conflict, as well as third parties accidentally injured in road accidents. The main event for the Russian insurance market was the introduction of Third Party Only Insurance (TPOI) in 2003. Compulsory TPOI has become the norm within the society. However, it should be noted that throughout its implementation a number of problems have been identified considering state regulation. The article provides an economic assessment of the TPOI market. The TPOI economic indicators have been unstable recently and they are developing with great fluctuations. In modern conditions, the systematic work of the All-Russian Union of Insurers and the Russian Association of Motor Insurers is required to overcome crisis phenomena including legislative changes, the development and implementation of innovative digital technologies, the improving interaction with local authorities and courts, and overcoming insurance fraud. The measures and the main directions for the further improvement of the TPOI system are proposed. A purposeful and effective policy including the widespread introduction of modern digital technologies, the improvement of work on the accumulation, storage and processing of data, digitalization and customer-focused key processes for providing insurance services is needed to overcome insurance fraud and to ensure economic security. There is a need to create and approve an interaction algorithm with the traffic police, which allow reducing the time of accident registration.
\end{abstract}

Keywords - road safety, Third Party Only Insurance (TPOI), digitalization of the TPOI system, overcoming insurance fraud, ensuring economic security.

\section{INTRODUCTION}

In modern conditions, the fundamental changes are needed considering the approaches to planning and conducting measures for the prevention of road accidents as well as to the introduction of new forms of work for all the elements of the road safety system.

The economic managing mechanisms in the field of ensuring road safety should occupy the most important place, creating conditions under which the emergency operation of

\author{
Narolina Ju.V. \\ Voronezh State University of Engineering Technology \\ Voronezh, Russia \\ E-mail: narolinajv@yandex.ru
}

vehicles is unprofitable. In this regard, a system of economic sanctions should be created and fully developed, including the insurance based on the activities of insurance transport companies and societies as a regulatory mechanism. In addition, it is necessary to introduce the full compensation for the damage. This will ensure the increase of the responsibility for all participants in the field of road safety and the conditions for the proper regulation of relations in society under the conditions of a market economy. [9]

The range of activities aimed at the improvement of road safety and, accordingly, the results are largely determined by the financial resources that can be allocated for its implementation. One of the sources of financing for this activity may be the insurance companies' funds since the solution of these issues requires the significant capital investments.

One of the directions may be a tax on insurance premiums, as well as loans that encourage the sponsorship of private firms, especially insurance companies in order to ensure road safety. The practice of successful and mutually beneficial cooperation between the governmental bodies and the insurance companies is widely used abroad. Thus, all insurance companies in Finland are subject to a special tax on traffic safety in the amount of one percent of insurance premiums. The funds collected in this way are used for advocacy, education of road users, and the implementation of an information support system. [9]

The protection of cargo from traffic accidents, considering a possibility of damage or loss of cargo, or even the encroachment on the cargo by third parties, is implemented in several versions. The first option is carrier liability insurance, the second is cargo insurance by its owner and the third is a mixed carrier liability insurance and owner insurance. In our opinion, the first option is the most preferable option for the bulk of cargo. The particularly expensive goods which are worth tens of millions of rubles require additional insurance. Large transport companies work closely with insurance companies. Many insurance companies offer discounts on cargo insurance with monitoring and control systems for automobiles. 
Financing problems are closely related to the formation of the correct depreciation policy in this area ensuring the full accrual of depreciation before the cancellation of vehicles and guarantees the targeted use of accumulated funds for updating rolling stock.

The presence of a large number of vehicles with service lives exceeding depreciation standards in the fleet is considered to be a negative factor. It is proposed to develop a system of economic mechanisms that stimulate vehicle owners to write off vehicles that develop their resources in order to solve this problem. It is advisable to purchase new vehicles on lease instead of worn and decommissioned ones.

The choice of the type of leasing (operating, financial or redemption) must be preceded by careful economic calculations. Thus, the type that ensures the minimum amount of the acquisition and operation car costs is selected. The specialized motor transport enterprises, as well as the enterprises of industry, agriculture and other sectors of the economy that have their own fleet, can either use leasing or use the services of involved vehicles. The choice of the best option should also be carried out according to the criterion of the minimum cost of transport services. The maintenance and repair should be done by the specialized car service enterprises as the important element of the preventive work to increase the level of technical readiness of the rolling stock of an enterprise that has its own fleet. The network of such enterprises is quite wide within the cities. They perform a wide variety of operations with higher quality, especially branded service stations as far as they have modern equipment and skilled professionals.

\section{II.ECONOMIC APPRAISAL OF THE TPOI MARKET ACTIVITY}

The main types of insurance in automobile transport are: compulsory civil liability insurance of vehicle owners (CTP), auto personal accident, extended non-owner liability insurance, freight insurance, voluntary motor third party liability insurance and others.

The main event for the Russian insurance market was the introduction of Third Party Only Insurance in 2003. The introduction of a new type of insurance, including compulsory insurance, is always associated with the need to obtain an appropriate license.

Federal Law of 04.25.2002 No. 40-FL "On Third Party Only Insurance" establishes requirements for insurers who apply for a TPOI license. [1]

These include the obligation of the insurer to have the ombudsman in each constituent entity of the Russian Federation to review victims' claims for recovery of compensation for harm and to make insurance payments. In addition, the insurer must have the insurance license and must be a member of a professional association of insurers operating in accordance with the requirements of the TPOI law. [1] The constant increase in the number of motor vehicles in the Russian Federation and the increase in the number of road accidents resulted in the adoption of the above law.

According to article 3 of the above law, the basic principles of compulsory insurance are:
- the indemnity bond for the life injury, harm to the health or property damage within the limits established by this law;

- universality and compulsory civil liability insurance of vehicle owners;

- inadmissibility of using vehicles in the Russian Federation whose owners have not fulfilled the obligation to insure their civil liability established by this law;

- economic interest of vehicle owners in improving road safety.

Currently, the global auto insurance market is on the third place after the life insurance and the health insurance.

According to the Russian Association of Motor Insurers, the financial result for 2017 amounted to minus 34.3 billion rubles (Fig. 1) [5, 6].

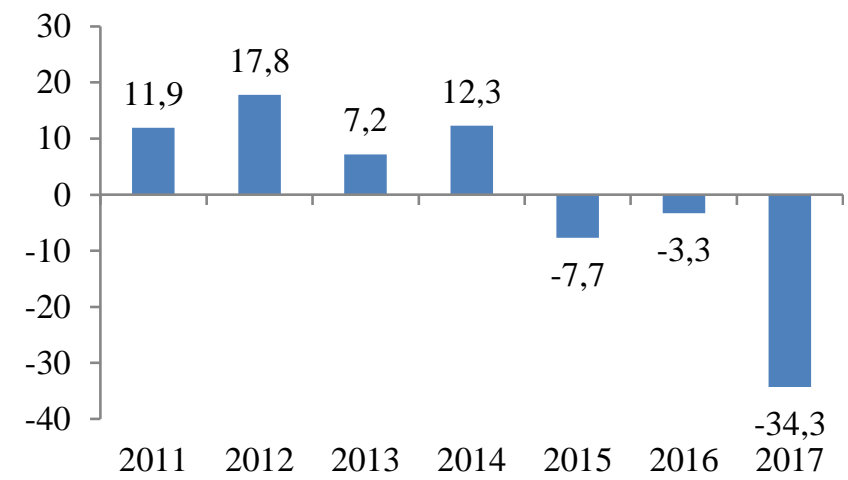

Fig. 1. The financial result of the TPOI market, billion rubles

TPOI loss ratios are also deteriorating. Figure 2 shows the Russian Association of Motor Insurers data on the collected premiums and payments made for 2010-2017. [5, 6]

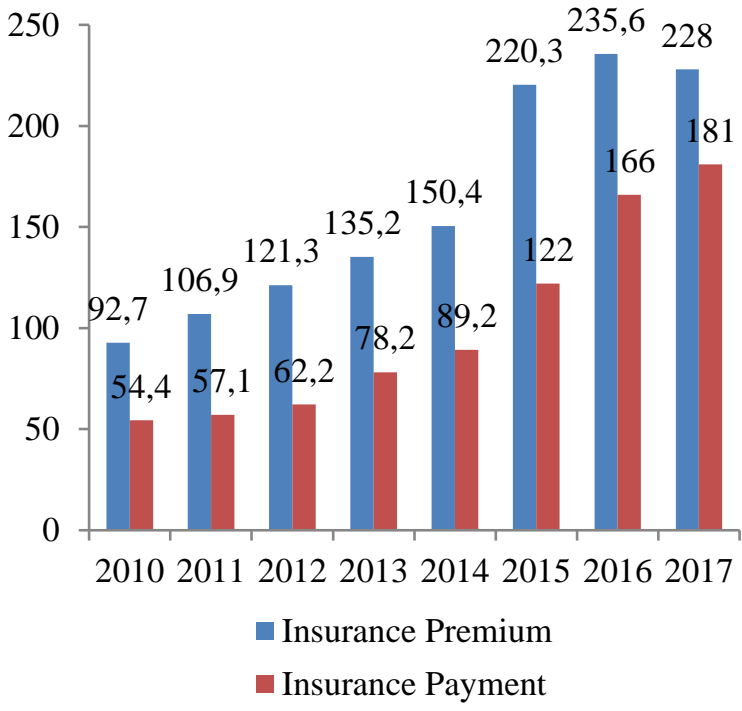

Fig. 2. Insurance premiums and payments by years, billion rubles 
It is necessary to note that the growth of payments steadily catches up with the growth of premiums or even outstrips them. The sum of insurance premiums differs by years, while the level of insurance payments steadily increases every year.

The focused actions by state authorities and insurers are required in order to overcome the TPOI crisis. The measures taken in 2018 resulted in the decrease of the average TPOI payment in Russia by $17 \%$ and amounted to 64 thousand rubles, while the fees (from January to July 2018) fell by $1 \%$ (to 128.9 billion rubles), and the payments decreased by $29 \%$ (79.7 billion rubles).

The socio-economic crises of recent years have led to the significant changes in the field of insurance in general, and the TPOI segment in particular. One of the most illustrative examples is the loss by Rosgosstrakh with 14 years of successful experience in operating its leading position. The rating of leading insurance companies according to the results of the first half of 2018 is shown in table 1. [5, 6]

TABLE I. TOP 10 INSURANCE COMPANIES IN YIELDING TPOI FEES

\begin{tabular}{|c|c|c|c|c|c|c|c|c|c|c|}
\hline & 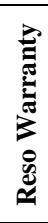 & 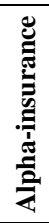 & 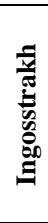 & 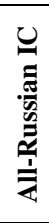 & 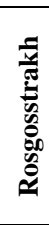 & 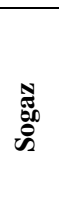 & $\sum_{\Sigma}^{\frac{\pi}{\pi}}$ & 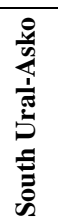 & 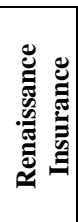 & 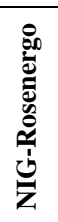 \\
\hline$M S, \%$ & 16 & 14 & 8.8 & 8.8 & 8.5 & 7.3 & 4.2 & 3.4 & 3.2 & 3.2 \\
\hline 2008 & 2 & 10 & 3 & 7 & 1 & 19 & 12 & 44 & 15 & 47 \\
\hline 2009 & 2 & 8 & 3 & 7 & 1 & 20 & 12 & 33 & 15 & 54 \\
\hline 2010 & 2 & 8 & 3 & 5 & 1 & 17 & 11 & 29 & 13 & 42 \\
\hline 2011 & 2 & 7 & 3 & 5 & 1 & 16 & 11 & 22 & 13 & 37 \\
\hline 2012 & 3 & 7 & 2 & 5 & 1 & 16 & 11 & 21 & 10 & 30 \\
\hline 2013 & 2 & 7 & 3 & 5 & 1 & 13 & 10 & 18 & 11 & 34 \\
\hline 2014 & 2 & 6 & 4 & 3 & 1 & 8 & 9 & 12 & 10 & 25 \\
\hline 2015 & 2 & 5 & 4 & 3 & 1 & 6 & 11 & 9 & 10 & 19 \\
\hline 2016 & 2 & 5 & 3 & 4 & 1 & 6 & 8 & 11 & 9 & 13 \\
\hline 2017 & 1 & 5 & 3 & 4 & 2 & 6 & 8 & 10 & 9 & 12 \\
\hline avg. & 2 & 6.8 & 3.1 & 4.8 & 1.1 & 12.7 & 10.3 & 20.9 & 11.5 & 31.3 \\
\hline
\end{tabular}

The data presented in the table reflect the activities of the companies that collected about $88 \%$ of all insurance premiums, according to two indicators: the TPOI market share and the place in the ranking according to the amount of premiums collected.

The Reso Warranty Company should be defined as the clear leader based on the data presented. Companies such as Ingosstrakh, Sogaz, All-Russian IC and Renaissance Insurance Group are distinguished by the stability of their positions. A large number of regional companies were able to occupy a significant share in the TPOI market because of the competent management.

The factors affecting the redistribution of the insurance market can be distinguished as following:

- creating a comfortable, accessible and safe environment for interaction between the insured and the insurers;

- the active development of the both branch and agent networks for the sale of insurance products;
- the effective system to deal with the acquired insurance portfolios for highly profitable types of insurance;

- the implementation of the focused and effective policy insuring the overcoming of the insurance fraud and economic security;

- the widespread adoption of the modern digital technologies and the improvement of work on the accumulation, storage and processing of data;

- the digitalization and customer-focused processes for the provision of insurance services. [6]

\section{DIRECTIONS FOR IMPROVING THE TPOI MARKET}

In recent years, insurers in collaboration with the Bank of Russia have developed and implemented measures for the further improvement of the TPOI system, which significantly affected the redistribution of the insurance services market, namely new correction factors were introduced and base rates were increased. A set of measures is being implemented to ensure the creation of an accessible environment for citizens and the loyalty of car owners and the victims of road accidents regarding the settlement of TPOI procedures. The most significant measures can be distinguished as the following:

- the implementation of the systems: "Single Agent" and "E-Guarantor";

- the digitalization of the insurance system for TPOI (eTPOI);

- the introduction of the system ensuring the implementation of the reconstruction repair as the way of compensation under TPOI;

- the development of a TPOI guide;

- the standardization of the work of appraisers, etc.

A great deal of work has been done to modernize the TPOI system and make it subject to compliance with the international standards. Thus, the number of citizens using European Accident Statement has increased over the four years from 4 to $35 \%$. The vigorous efforts are being made to liberalize the pricing and individualize the rates for the TPOI system under the support of the Ministry of Finance and the Bank of Russia.

In 2018, the Bank of Russia announced a step-by-step plan for TPOI rates reduction by 2020 . The beginning of the first stage, including the expansion of the rate scheme at the base rate by $20 \%$ in each direction, as well as the increase in segments by age and length of service up to 50, was planned for the summer of 2018. However, its implementation was delayed due to the failure in adopting the necessary legislative acts. The second stage involved the adoption of laws ensuring the possibility of individualization and expansion of the rate scheme, as well as the Bank of Russia power increase in the field of TPOI. At the third stage (mid-2020), the tariff is liberalized, while maintaining social indices. Additionally, the Bank of Russia intends to tighten control over intermediaries in the field of TPOI. [8] 
Since mid-2018, the Central Bank of the Russian Federation in collaboration with the insurers, has been working on the reform of the entire TPOI system. A study initiated by the Central Bank is being conducted about the factors affecting tariffs. The State Duma, the Federation Council and the Bank of Russia hold hearings on the new TPOI regulation and tariffication system. The All-Russian Union of Insurers and the Russian Association of Motor Insurers take an active part in these events. They insist on a gradual transition to a free rate system, without violating the interests of vulnerable population. This process should begin as soon as possible. Firstly, the rate scheme should be expanded allowing the pricing policy to influence the situation in problem regions.

The Federal Law "On the Ombudsmen for the Rights of Consumers of Financial Services" was signed into law on September 3, 2018. [3] Its adoption resulted in the establishing of the financial ombudsmen institute in Russia. The insurance services market turns out to be the first, where the pre-trial settlement of disputes should be mandatory.

However, there are a number of issues that remain unresolved. The system of in-kind compensation (car repair instead of insurance payment) is not acting well.

A focused work has been launched to overcome the insurance fraud. There are units to overcome the insurance fraud in TPOI system in all the constituent entities of the Russian Federation. These units coordinate the work and ensure the interaction of local authorities and insurance companies.

The compilation of ratings of regions has become widespread. The results of the ratings are reported to local authorities.

One of the important indicators of insurance fraud in terms of losses is the indicator of average TPOI payment. This indicator has different dynamics in accordance with the different constituent entities of the Russian Federation. At present, the average payment in a prosperous region is 4.5 times different from the indicator of a dysfunctional region. [6]

The overcoming of the insurance fraud should not be limited to efforts by insurance unions only. Thus, the implementation of a tough policy to ensure economic security has enabled the regional companies such as YuzhUral-Asko and NASKO to achieve high rates of growth in market share and to reduce a significant share of losses from unlawful actions on the part of insured.

\section{CONCLUSION}

Currently, there are a number of problems associated with the organization of information interaction between the Russian Association of Motor Insurers and the traffic police. The information about the owners of vehicles issued by driver's licenses are classified as of limit access in accordance with the provisions of the Federal Law "On Information, Informatization and Information Protection" No. 149-FL. [2]

It is necessary to develop a reference system that meets modern digitalization requirements to implement the law. The storage of data on TPOI contracts should be provided by the federal executive body for the supervision of insurance activities. The traffic police must have access to the information about the owners of vehicles, violators of the road rules, traffic accidents, the amount of damage in case of specific accidents and the relevant statistical data on the mentioned accounting objects. [10]

Today, the European Accident Statement can be used to register the accidents without injuries and with minor damage without the participation of the traffic police in order to significantly reduce the time of the incident registration.

In modern conditions, the regulatory framework in the field of insurance needs significant changes. According to the experts of the car insurance market, there are up to $30 \%$ of the articles of the law and paragraphs of the rules that require improvement. The measures should be aimed at eliminating legal imbalances, as well as changing the conditions of insurance and simplifying the procedure for settlement of losses.

The TPOI law, as observed all over the world, should become an economic stimulator of safe and trouble-free driving ensuring the road safety in the Russian Federation.

\section{References}

[1] Federal law of 04.25.2002. no. 40-FZ (as amended on 05/01/2019) "On compulsory insurance of civil liability of vehicle owners" (as amended and supplemented, entered into force on 10.29.2019). ATP Consultant Plus.

[2] Federal Law of 27 July 2006, no. 149-FZ (as amended on May 1, 2019) "On Information, Information Technologies and the Protection of Information". ATP Consultant Plus.

[3] Federal law dated 04.06.2018, no. 123-Ф3 “On the Commissioner for the Rights of Consumers of Financial Services”. ATP Consultant Plus.

[4] Federal State Statistics Service. Retrieved from: http://www.gks.ru

[5] Multiparameter information-analytical system for forecasting and modeling the situation in the field of road safety (MIAS). Retrieved from: http://www.prognoz.ru/project/406

[6] P.A. Samiev, "The crisis and the reform of OSAGO - opportunities and threats for regional insurers", Insurance Today, 2018. Retrieved from: http://www.insur-info.ru/analysis/1242

[7] Territorial authority of the Federal State Statistics Service for the Voronezh Region. Retrieved from: http://voronezhstat.gks.ru

[8] T. Kulikova, "Plans for the liberalization of OSAGO tariffs", The Newspaper Pravda, vol. 116, no. 30759, p. 4, 23-24 October 2018.

[9] V.P. Bychkov, V.A. Verzilin, V.M. Zalozhnich, "The Economic Problems in Ensuring the Road safety", World of Transp. and Technol. Mach., vol. 1, no. 40, pp. 97-102, January 2013

[10] V.P. Bychkov, V.A. Verzilin, S.S. Morkovina, A.M. Bukreev, Innovation development in the field of motor transport. Voronezh: Voronezh State Forestry Univer. named after G.F. Morozov, 2018, 308 p. 